\title{
PEMANFAATAN SOCIAL LEARNING NETWORK"EDMODO" DALAM MEMBANTU PERKULIAHAN TEORI BODI OTOMOTIF DI PRODI PTM JPTK FKIP UNS
}

\author{
Basori \\ Prodi Pend. Teknik Informatika dan Komputer, Jurusan Pendidikan Teknik Kejuruan, FKIP, UNS \\ Kampus UNS Pabelan Jl. Ahmad Yani 200, Surakarta, Tlp (0271)718419 Fax. (0271)716266
}

\begin{abstract}
This research aims to implement social learning network "Edmodo" in the lecture. Specifically, It aims to kmow the contribution of Edmodo in learning activity, to know student perceptions of the completeness of the features and theme of Edmodo, and to know the level of satisfaction with the Edmodo service.

This research used descriptive methods. The data were taken using the questionnaire and interview. Data obtained from PTM students who take courses in automotive body with the number of 34person. This research used $s$ a descriptive data analysis.

The results shows that : 1) There are a significant increase in the contribution of Edmodo in lecture. From the data it can be seen $52.94 \%$ are high, and $38.24 \%$ in the very high category . 2 ) Edmodo feature strongly supports the management of teaching and learning. It appears there are $44.12 \%$ of respondents expressed a very high category, and $35.29 \%$ in the very high category, 3 ) Edmodo theme is very userfriendly, so easy in use. There are $67.65 \%$ of the data is known to the high category, and $14.71 \%$ in the very high category. 4 ) Students feel a high level of satisfaction with the Edmodo service. . From the data it can be seen very high category $61.76 \%$, and $35.29 \%$ are high.
\end{abstract}

Keywords: social learning network, edmodo, learning, Automotive Body

\section{PENDAHULUAN}

Perkembangan dunia teknik informatika dan komputer (TIK) yang semakin pesat membawa dampak sangat terasa di dunia pendidikan saat ini. Di sisi lain, berubahnya paradigma pendidikan yang dulunya menganut teacher centered learning menjadi student centered learning, membawa perubahan yang sangat signifikan terhadap metode-metode pembelajaran yang dikembangkan saat ini. Pembelajaran yang dulunya lebih bersifat ceramah dan satu arah dari dosen ke mahasiswa berubah menjadi lebih dinamis. Dosen selaku pengampu mata kuliah sudah beralih fungsi sebagai fasilitator dalam pembelajaran. Dosen mengarahkan mahasiswa menuju tingkat pengetahuan yang tinggi dengan mendaya gunakan fasilitas yaang menunjang untuk bereksplorasi. Dalam hal ini fasilitas yang dimaksud adalah kemudahan penggunaan internet di kampus.

Sistem e-learning yang merupakan alat bantu mahasiswa dalam pembelajaran menjadi salah satu media yang sangat efektif untuk penyampaian knowledge/pengetahuan. Jaya Kumar C. Koran (2002), mendefinisikan elearning sebagai sembarang pengajaran dan pembelajaran yang menggunakan rangkaian elektronik (LAN, WAN, atau internet) untuk menyampaikan isi pembelajaran, interaksi, atau bimbingan. Ada pula yang menafsirkan elearning sebagai bentuk pendidikan jarak jauh yang dilakukan melalui media internet. Sedangkan Dong (dalam Kamarga, 2002) mendefinisikan e-learning sebagai kegiatan belajar asynchronous melalui perangkat elektronik komputer yang memperoleh bahan belajar yang sesuai dengan kebutuhannya.

Dalam perkembangannya, sistem elearning ini digunakan sebagian besar institusi pendidikan di Indonesia. Di luar negeri seperti di AS, e-learning telah digunakan di hampir $90 \%$ universitas yang memiliki lebih dari 10.000 siswa. Karena urgensinya yang begitu terasa, maka muncullah berbagai macam model pengembangan e-learning. Mulai dari hanya sekedar berbasis power point di kelas, menuju ke sistem LMS (Learning Management System). LMS ini merupakan sistem pengelolaan pembelajaran secara integratif berbasis website. Tentu saja dalam pengembangannya dibutuhkan sumber daya yang mengetahui tentang operasional sistem e-learning ini. LMS yang dipakai sampai saat ini sudah banyak macam ragamnya. Mulai dari Moodle, Claroline, Atutor, eFront dan masih banyak yang lainnya. Masingmasing mempunyai kelebihan dan kekurangannya. Yang paling populer digunakan adalah Moodle. Saat ini terdapat lebih dari 18 ribu situs e-learning tersebar di lebih dari 163 negara yang dikembangkan dengan Moodle.

Tapi perlu diingat, Subagyo (2007) menyatakan penggunaan LMS di atas 
membutuhkan infrastruktur yang tidak sedikit dan perawatan yang berkelanjutan. Tentu saja ini membutuhkan alokasi pendanaan dalam pengelolaannya. Untuk itu diperlukan sistem alternatif yang dapat digunakan untuk pembelajaran online, tanpa biaya perawatan yang banyak. Di samping itu juga dibutuhkan yang userfriendly, agar pengoperasiannya mudah dan tidak membingungkan bagi yang menggunakannya.

Di sisi lain LMS ataupun pendidikan jarak jauh harus memiliki unsur sebagai berikut: :

1. Pusat kegiatan siswa. Suatu community web based distance learning harus mampu menjadikan sarana ini sebagai tempat kegiatan mahasiswa, di mana mahasiswa dapat menambah kemampuan, membaca materi kuliah, mencari informasi dan sebagainya.

2. Interaksi dalam grup. Para mahasiswa dapat berinteraksi satu sama lain untuk mendiskusikan materi-materi yang diberikan dosen. Dosen dapat hadir dalam grup untuk memberikan sedikit ulasan tentang materi yangdiberikannya.

3. Sistem administrasi mahasiswa. Mahasiswa dapat melihat berbagai informasi mengenai status mahasiswa, prestasi dan sebagainya.

4. Pendalaman materi dan ujian. Dosen biasanya sering mengadakan kuis singkat, dan memberikan tugas untuk tujuan pendalaman materi, serta melakukan test pada akhir masa belajar. Hal ini juga harus dapat diantisipasi oleh online learning.

5. Perpustakaan digital. Pada bagian ini terdapat berbagai informasi kepustakaan yang tidak terbatas pada buku, tetapi juga kepustakaan digital seperti suara, gambar dan sebagainya. Bagian ini bersifat penunjang belajar dan berbentuk database.

6. Materi online di luar materi kuliah. Bahan bacaan tersedia pada web lainnya agar materi dapat menunjang perkuliahan. Dosen dan mahasiswa dapat langsung terlibat dalam memberikan bahan tersebut untuk publikasi kepada mahasiswa lainnya.

Edmodo merupakan jawaban yang sangat tepat untuk pertanyaan-pertanyaan $\mathrm{di}$ atas. Edmodo didirikan pada tahun 2008 oleh Nicolas Brog dan Jeff O'Hara. Edmodo adalah sebuah platform Microblogging yang secara khusus dikembangkan dan dirancang untuk digunakan oleh guru dan siswa dalam suatu ruang kelas. Edmodo menyediakan cara yang aman dan mudah untuk berkomunikasi dan berkolaborasi antara siswa dan guru, berbagi konten berupa teks, gambar, links, video, maupun audio. Edmodo bertujuan untuk membantu pendidik memanfaatkan fasilitas social networking sesuai dengan kondisi pembelajaran di dalam kelas.

\section{Landasan Teori}

\section{Social Learning Network "Edmodo"}

Edmodo lahir ketika hampir setiap orang sudah tidak dapat dipisahkan lagi dengan alat yang namaya telpon seluler (ponsel). Perkembangan ponsel yang begitu cepat, menghadirkan terobosan-terobosan baru yang digunakan untuk memudahkan kehidupan manusia dalam beraktivitas. Salah satu yang paling populer adalah facebook. Hampir setiap orang mempunyai ponsel pasti mengetahui facebook. Edmodo merupakan salah satu open source gratis yang berusaha mengimbangi perkembangan facebook. Hanya saja bedanya edmodo lebih digunakan dalam dunia pendidikan. Sehingga fitur yang adapun mendukung pengelolaan pembelajaran secara terintegratif.

\section{Fitur Edmodo}

Fitur edmodo disesuaikan dengan kebutuhan pembelajaran. Edmodo mengklasifikasikan fiturnya berdasarkan pengguna yaitu guru dan siswa. Dibawah ini adalah fitur yang ada pada Edmodo.

\section{a). Assignment}

Assignment digunakan oleh guru untuk memberikan penugasan kepada siswa secara online. Fitur ini dilengkapi dengan waktu deadline danfitur attach file sehingga siswa dapat mengirimkan tugas dalam bentuk file secara langsung kepada guru. selain itu, kiriman Assignment jugaterdapat tombol "Turn in" yang menandakan bahwa siswa telah menyelesaikan tugas mereka.

b). File and Links

Pada fitur ini guru dan siswa dapat mengirimkan pesan dengan melampirkan file dan link pada grup kelas, siswa atau guru lainnya. File yang dilampirkan berlaku untuk semua jenis ekstensi seperti .doc, .pdf, .ppt, .xls, dll. Berikut ini contoh pengiriman note dengan melampirkan file.

c). Quiz

Quiz digunakan untuk memberikan evaluasi secara online baik berupapilihan ganda, isian singkat, maupun soal uraian. Quiz hanya dapatdibuat oleh guru, sedangkan siswa hanya mengerjakannya saja. Fitur inidilengkapi dengan 
batas waktu pengerjaan, informasi tentang kuis yangakan dibuat, judul kuis dan tampilan kuis.

d). Polling

Polling hanya dapat dibuat oleh guru untuk dibagikan kepada siswa. Biasanya guru menggunakan poling untuk mengetahui tanggapan siswa mengenai hal tertentu yang berkenaan dengan pelajaran.

\section{e). Gradebook}

Fitur gradebook digunakan sebagai catatan nilai siswa. Pemberian nilai dapat dilakukan oleh guru dan dapat diisi secara manual atau secara otomatis. Pengisian nilai secara otomatis hanya bisa dilakukan berdasarkan hasil skor Assignment dan Quiz. Penilaian pada gradebookdapat di-export menjadi file.csv. Berikut ini adalah tampilan gradebookdengan user sebagai guru.

\section{f). Library}

Fitur ini digunakan sebagai tempat penyimpanan berbagai sumber pembelajaran dengan konten yang beragam. Dengan fitur library, guru dapat meng-upload bahan ajar, materi, presentasi, sumber referensi, gambar, video, audio dan konten digital lainnya.Link dan File yang terdapat di Library dapat dibagikan baik kepada siswa maupun grup. Siswa juga dapat menambahkan konten yang dibagikan oleh guru ke dalam library-nya.

\section{g). Award Badges}

Fitur ini digunakan untuk memberikan suatu penghargaan baik kepada siswa maupun kelompok. Penghargaan dapat ditentukan oleh guru itu sendiri sehingga tidak menghambat kreatifitas guru dalam memberikan penghargaan. Berikut adalah tampilan Award Badges.

h). Parents Codes

Fitur ini berfungsi memberi kesempatan kepada orangtua/wali masing-masing siswa dapat bergabung memantauaktivitas belajar dan prestasi putra-putrinya, guru harus mengakses kode untuk orang tua siswa dan kemudian membagikannya pada masing-masing orangtua/wali.

\section{Kelebihan dan kekurangan Edmodo}

Menurut Umaroh (2012), adapun kelebihan dari jejaring edmodo adalah :

1. Membuat pembelajaran tidak bergantung pada waktu dan tempat.

2. Meringankan tugas guru untuk memberikan penilaian kepada siswa.

3. Memberikan kesempatan kepada orangtua/ wali siswa untuk memantau aktivitas belajar dan prestasi dari putra-putrinya.
4. Membuat kelas lebih dinamis karena memungkinkan interaksi guru dengan siswa maupun antara siswa dengan siswa dalam hal pelajaran atau tugas.

5. Memfasilitasi kerja kelompok yang multidisiplin.

6. Mendorong lingkungan virtual kolaboratif yang membantu pembelajaranberbasis proses.

Sedangkan kekurangan dari jejaring edmodo adalah :

1. Penggunaan bahasa program yang masih berbahasa inggris sehingga terkadang menyulitkan guru dan siswa.

2. Belum tersedianya sintaks online secara langsung pada edmodo.

\section{Bodi Otomotif}

Bidang keahlian otomotif mempunyai beberapa kompetensi keahlian. Ada 5 macam, yaitu: (1) Teknik kendaraan ringan, (2) Teknik sepeda motor, (3) Teknik bodi otomotif, (4) Teknik alat berat, dan (5) Teknik ototronik.

Mata kuliah bodi otomotif adalah salah satu mata kuliah keahlian yang ada di prodi Pendidikan Teknik Mesin FKIP UNS. Mata kuliah ini tidak berdiri sendiri. Untuk melengkapi skill/ketrampilan mahasiswa dalam penguasaan kompetensi keahlian, mahasiswa juga mengambil mata kuliah praktik bodi otomotif. Adapun kompetensi yang harus dikuasai mahasiswa dalam mata kuliah ini adalah: (1) Sejarah bodi otomotif, (2) Peralatan tangan dan peralatan tenaga, (3) Kesehatan dan keselamatan kerja, (4) Pengelasan, (5) Metal straightening, (6) Filler (pendempulan), (7) Panel repair, (8) Rust repair, (9) Pengerjaan Alumunium, (10) Fiberglass, (11) Pengecatan.

\section{METODE PENELITIAN}

Penelitian ini menggunakan metode deskriptif. Metode deskriptif dapat diartikan sebagai prosedur atau cara memecahkan masalah penelitian dengan memaparkan keadaan objek yang diselidiki (seseorang, lembaga, masyarakat) sebagaimana asalnya, berdasarkan fakta-fakta yang aktual pada saat sekarang.

Dalam penelitian ini, data yang diperoleh berupa data hasil angket/kuisioner tentang pelaksanaan edmodo dalam pembelajaran dan data wawancara. Data diperoleh dari mahasiswa PTM yang mengambil mata kuliah Body otomotif sejumlah 34 orang. Secara umum, berikut langkah pengolahan data dalam penelitian ini

1. Analisis data yang digunakan dalam penelitian ini adalah analisis data deskriptif. 
Data yang diperoleh dari angket dan wawancara dianalisis secara deskriptif. Menyajikan data dari angket dan wawancara ke dalam sebuah tabel.

Data yang diperoleh baik dari angket maupun wawancara disajikan ke dalam sebuah tabel. Untuk mempermudah pengolahan, data yang berasal dari angket, dikonversi sesuai dengan aturan skala Likert yang telah ditentukan.

2. Menentukan kriteria penilaian data.

Penentuan kriteria penilaian angket menggunakan rumus sebagai berikut:

Tabel 1.Kriteria Penilaian Komponen

\begin{tabular}{|c|c|}
\hline Rentangan Skor & Kategori \\
\hline$X \leq \mu-1,5 \sigma$ & Sangat rendah \\
$\mu-1,5 \sigma<X \leq \mu-0,5 \sigma$ & rendah \\
$\mu-0,5 \sigma<X \leq \mu+0,5 \sigma$ & Sedang \\
$\mu+0,5 \sigma<X \leq \mu+1,5 \sigma$ & Tinggi \\
$\mu+1,5 \sigma<X$ & Sangat tinggi \\
\hline
\end{tabular}

Keterangan :

$\mu=$ Mean ideal yang dapat dicapai instrumen

$=1 / 2($ skor tertinggi + skor terendah $)$

$\sigma=$ Standar deviasi ideal yang dapat dicapai instrumen

$=1 / 6$ (skor tertinggi - skor terendah $)$

$\mathrm{X}=$ Skor yang dicapai

Perhitungan Kriteria data yang diperoleh melalui angket untuk masing-masing variabel dapat dilihat pada tabel 4 berikut:

Tabel 2. Skor Item Instrumen

\begin{tabular}{|c|c|c|c|c|}
\hline \multirow{2}{*}{ Uraian } & \multicolumn{4}{|c|}{ Instrumen } \\
\cline { 2 - 5 } & $\mathrm{A}$ & $\mathrm{B}$ & $\mathrm{C}$ & $\mathrm{D}$ \\
\cline { 1 - 3 } Jumlah & 5 & 6 & 4 & 5 \\
\hline $\begin{array}{c}\text { Item } \\
\text { Skor } \\
\text { Maksimum }\end{array}$ & 25 & 30 & 20 & 25 \\
\hline $\begin{array}{c}\text { Skor } \\
\text { Minimum }\end{array}$ & 5 & 6 & 4 & 5 \\
\hline $\begin{array}{c}\text { Rentang } \\
\text { nilai }\end{array}$ & 20 & 24 & 16 & 20 \\
\hline Mean $(\mu)$ & 15 & 18 & 12 & 15 \\
\hline $\begin{array}{c}\text { Standar } \\
\text { deviasi }(\square)\end{array}$ & 3,33 & 4 & 2,67 & 3,33 \\
\hline
\end{tabular}

\section{HASIL DAN PEMBAHASAN}

Data hasil penelitian mendeskripsikan tentang: (1) Peran edmodo dalam pembelajaran, (2) Kelengkapan fitur dalam edmodo,
Tampilan edmodo untuk pembelajaran online, (4) Kepuasan layanan edmodo.

Pelaksanaan perkuliahan bodi otomotif. Perkuliahan bodi otomotif dilaksanakan secara blended learning, yaitu perkuliahan dengan perpaduan antara tatap muka di kelas dan online. Perkuliahan tatap muka dilaksanakan selama 2 jam perkuliahan setiap minggu dalam satu semester. Untuk menunjang perkuliahan tatap muka tersebut, mahasiswa diwajibkan untuk belajar mandiri dengan bantuan mobile learning dan Social Learning Netwok "edmodo". Berikut ini beberapa dokumentasi aktivitas perkuliahan dengan menggunakan edmodo.

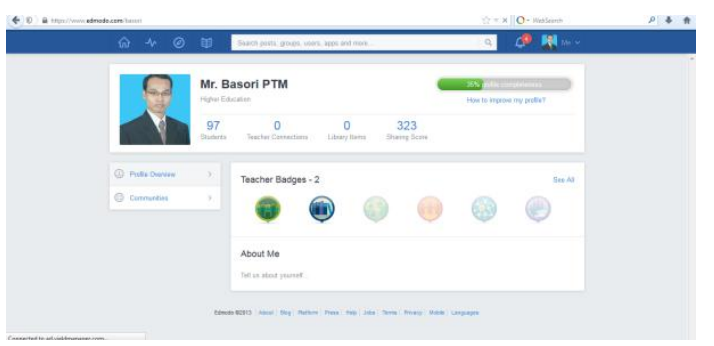

Gambar 1. URL edmodo, http://edmodo.com/basori

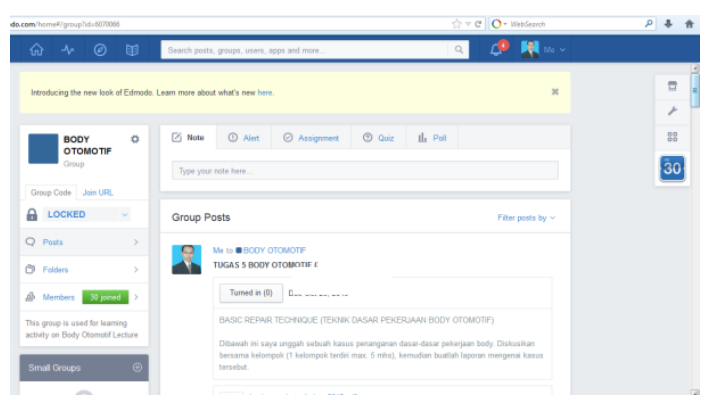

Gambar 2. Frontpage Mata kuliah Body Otomotif di edmodo

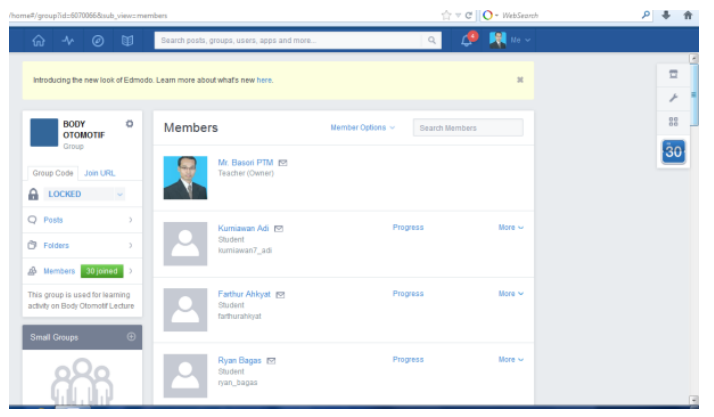

Gambar 3. Peserta Mata kuliah Body Otomotif di edmodo

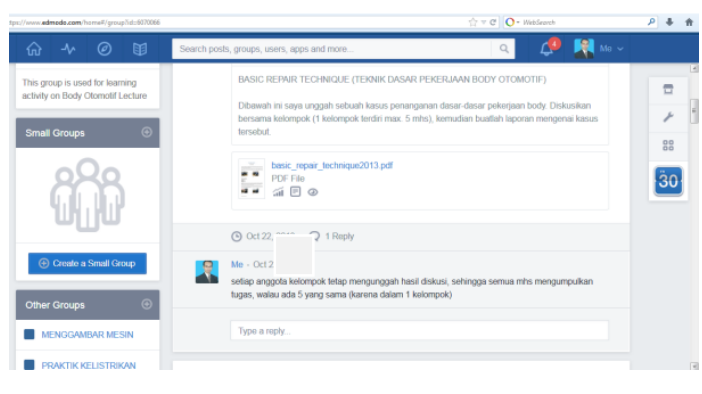

Gambar 4. Unggah dan unduh file materi di edmodo 


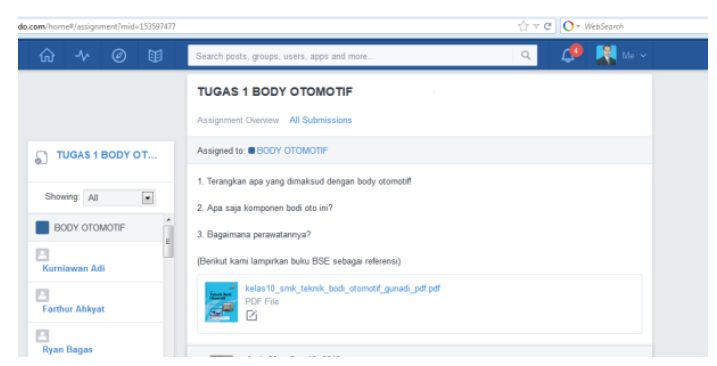

Gambar 5. Tugas/assignment di edmodo

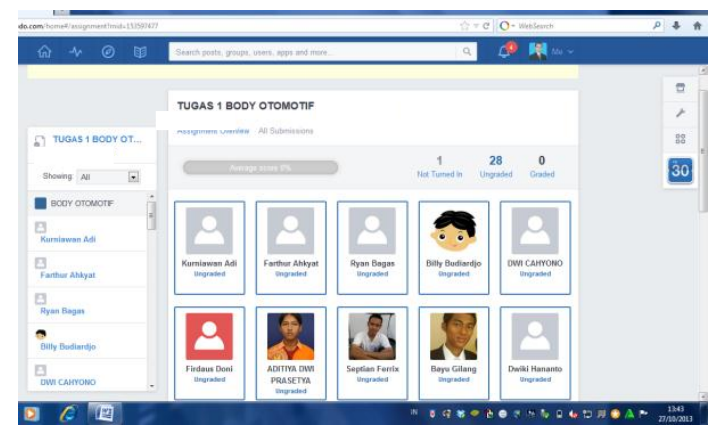

Gambar 6. Mahasiswa yang telah mengunggah tugas di edmodo

Setelah proses perkuliahan dilalui, mahasiswa mengevaluasi pelaksanaan perkuliahan dengan edmodo ini. Evaluasi mahasiswa mengikuti angket yang telah diberikan. Berikut hasilnya:

1. Peran edmodo dalam pembelajaran

Data penelitian menunjukkan, rentang skor antara 13 sampai dengan 25. Distribusi perolehan frekuensi dan persentase peran edmodo dalam pembelajaran disajikan dalam tabel berikut ini.

Tabel 3. Distribusi skor peran edmodo dalam pembelajaran

\begin{tabular}{|l|c|c|c|}
\hline Kategori & $\begin{array}{c}\text { Rentang } \\
\text { Skor }\end{array}$ & $\begin{array}{c}\text { Frekuen } \\
\text { si }\end{array}$ & $\begin{array}{c}\text { Persenta } \\
\text { se } \\
(\%)\end{array}$ \\
\hline $\begin{array}{l}\text { Sangat } \\
\text { tinggi }\end{array}$ & $>20,00$ & 13 & 38,24 \\
\hline Tinggi & $\begin{array}{c}16,68- \\
20,00\end{array}$ & 18 & 52,94 \\
\hline Sedang & $\begin{array}{c}13,34- \\
16,67\end{array}$ & 2 & 5,88 \\
\hline Rendah & $\begin{array}{c}10,01- \\
13,33\end{array}$ & 1 & 2,94 \\
\hline $\begin{array}{l}\text { Sangat } \\
\text { rendah }\end{array}$ & $\leq 10,00$ & 0 & 0 \\
\hline
\end{tabular}

Berdasarkan data dalam tabel, diketahui rentang skor terdistribusi ke arah positif. Data menunjukkan dalam kategori sangat tinggi $38,24 \%$, tinggi sejumlah $52 \%$, dan sedang terlihat
$5,88 \%$. Kategori rendah hanya $2,94 \%$ dan sangat rendah tidak ada.

Hal ini menunjukkan bahwa peranan penggunaan edmodo dalam membantu perkuliahan sangat signifikan terbukti dengan banyaknya persentase dalam kategori tinggi dan sangat tinggi.

Berikut ini adalah visualisasi perolehan data tersebut di atas.

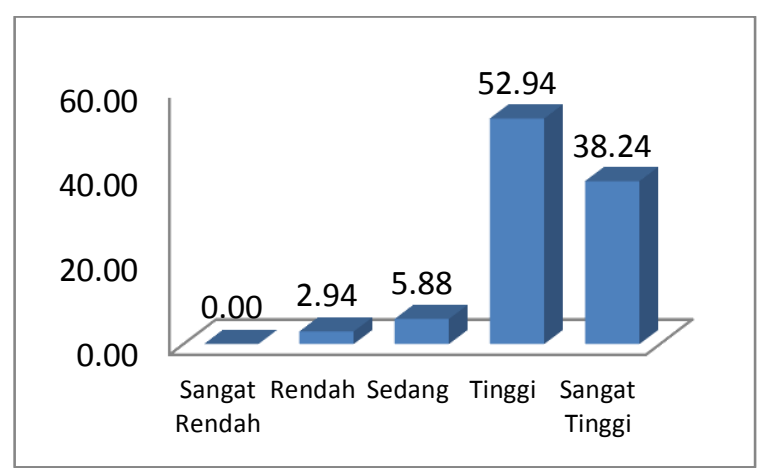

Gambar 7. Diagram Persentase Skor peran edmodo dalam pembelajaran

\section{Kelengkapan fitur dalam edmodo}

Data penelitian menunjukkan, rentang skor antara 15 sampai dengan 29. Distribusi perolehan frekuensi dan persentase kelengkapan fitur dalam edmodo untuk memenuhi syarat pembelajaran disajikan dalam tabel berikut ini.

Tabel 4. Distribusi skor fitur edmodo

\begin{tabular}{|l|c|c|c|}
\hline Kategori & $\begin{array}{c}\text { Rentang } \\
\text { Skor }\end{array}$ & $\begin{array}{c}\text { Frekuen } \\
\text { si }\end{array}$ & $\begin{array}{c}\text { Persenta } \\
\text { se } \\
(\%)\end{array}$ \\
\hline $\begin{array}{l}\text { Sangat } \\
\text { tinggi }\end{array}$ & $>24,00$ & 12 & 35,29 \\
\hline Tinggi & $\begin{array}{c}20,01- \\
24,00\end{array}$ & 15 & 44,12 \\
\hline Sedang & $\begin{array}{c}16,01- \\
20,00\end{array}$ & 6 & 17,65 \\
\hline Rendah & $\begin{array}{c}12,01- \\
16,00\end{array}$ & 1 & 2,94 \\
\hline $\begin{array}{l}\text { Sangat } \\
\text { rendah }\end{array}$ & $\leq 12,00$ & 0 & 0 \\
\hline
\end{tabular}

Berdasarkan data dalam tabel, diketahui rentang skor terdistribusi ke arah positif. Data menunjukkan dalam kategori sangat tinggi $35,29 \%$, tinggi sejumlah $44,12 \%$, dan sedang terlihat $17,65 \%$. Kategori rendah hanya $2,94 \%$ dan sangat rendah tidak ada.

Hal ini juga menunjukkan bahwa fitur yang dimiliki oleh social learning network "edmodo" mencukupi kebutuhan dari pengelolaan sistem perkuliahan. 
Berikut ini adalah visualisasi perolehan data tersebut di atas.

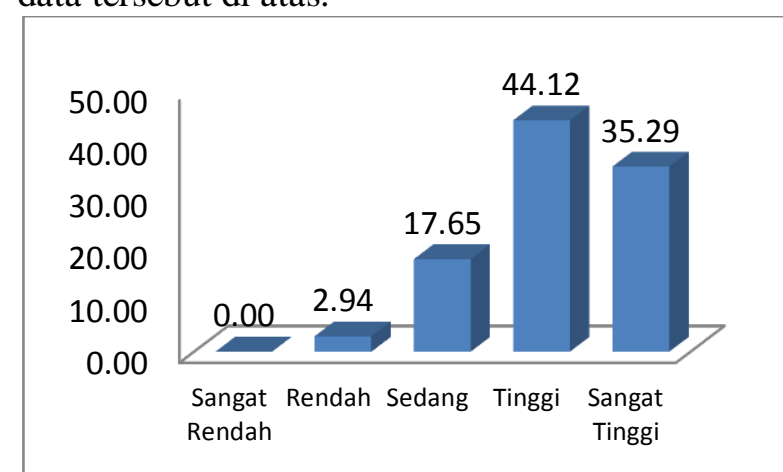

Gambar 8. Diagram Persentase Skor Fitur edmodo

3. Tampilan edmodo untuk pembelajaran online

Data penelitian menunjukkan, rentang skor antara 7 sampai dengan 18. Distribusi perolehan frekuensi dan persentase tampilan edmodo untuk pembelajaran online disajikan dalam tabel berikut ini.

Tabel 5. Distribusi skor tampilan edmodo

\begin{tabular}{|l|c|c|c|}
\hline Kategori & $\begin{array}{c}\text { Rentang } \\
\text { Skor }\end{array}$ & $\begin{array}{c}\text { Frekuen } \\
\text { si }\end{array}$ & $\begin{array}{c}\text { Persenta } \\
\text { se } \\
(\%)\end{array}$ \\
\hline $\begin{array}{l}\text { Sangat } \\
\text { tinggi }\end{array}$ & $>16,00$ & 5 & 14,71 \\
\hline Tinggi & $\begin{array}{c}13,34- \\
16,00\end{array}$ & 23 & 67,65 \\
\hline Sedang & $\begin{array}{c}10,68- \\
13,33\end{array}$ & 5 & 14,71 \\
\hline Rendah & $\begin{array}{c}8,01- \\
10,67\end{array}$ & 1 & 2,94 \\
\hline $\begin{array}{l}\text { Sangat } \\
\text { rendah }\end{array}$ & $\leq 8,00$ & 0 & 0 \\
\hline
\end{tabular}

Berdasarkan data dalam tabel, diketahui rentang skor terdistribusi ke arah positif. Data menunjukkan dalam kategori sangat tinggi $14,71 \%$, tinggi sejumlah $67,65 \%$, dan sedang terlihat $14,71 \%$. Kategori rendah hanya $2,94 \%$ dan sangat rendah tidak ada.

Dari sini dapat ditunjukkan bahwa tampilan (theme) dari edmodo cukup baik terlihat dari banyakn skor pada daerah tinggi.

Berikut ini adalah visualisasi perolehan data tersebut di atas.

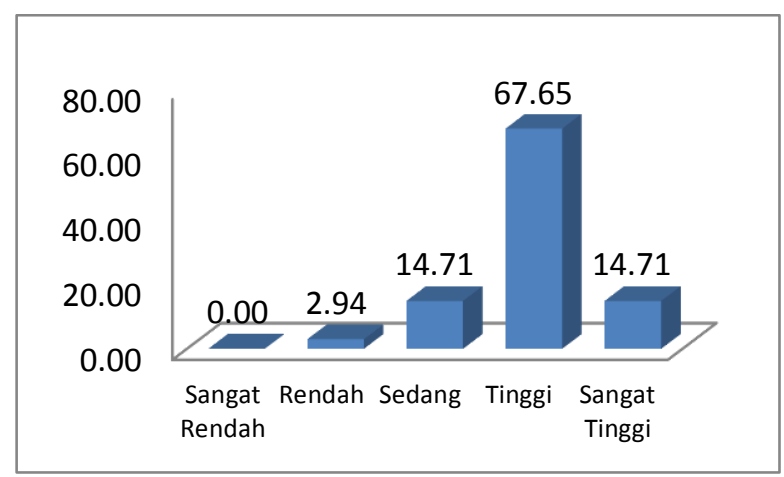

Gambar 9. Diagram Skor tampilan edmodo

4. Kepuasan layanan edmodo.

Data penelitian menunjukkan, rentang skor antara 11 sampai dengan 24. Distribusi perolehan frekuensi dan persentase kepuasan mahasiswa dalam menggunakan edmodo disajikan dalam tabel berikut ini.

Tabel 6. Distribusi skor kepuasan terhadap layanan edmodo

\begin{tabular}{|l|c|c|c|}
\hline Kategori & $\begin{array}{c}\text { Rentang } \\
\text { Skor }\end{array}$ & $\begin{array}{c}\text { Frekuen } \\
\text { si }\end{array}$ & $\begin{array}{c}\text { Persenta } \\
\text { se } \\
(\%)\end{array}$ \\
\hline $\begin{array}{l}\text { Sangat } \\
\text { tinggi }\end{array}$ & $>20,00$ & 21 & 61,76 \\
\hline Tinggi & $\begin{array}{c}16,68- \\
20,00\end{array}$ & 12 & 35,29 \\
\hline Sedang & $\begin{array}{c}13,34- \\
16,67\end{array}$ & 0 & 0 \\
\hline Rendah & $\begin{array}{c}10,01- \\
13,33\end{array}$ & 1 & 2,94 \\
\hline $\begin{array}{l}\text { Sangat } \\
\text { rendah }\end{array}$ & $\leq 10,00$ & 0 & 0 \\
\hline
\end{tabular}

Berdasarkan data dalam tabel, diketahui rentang skor terdistribusi ke arah positif. Data menunjukkan dalam kategori sangat tinggi $61,76 \%$ dan tinggi sejumlah 35,29\%. Kategori rendah hanya $2,94 \%$ dan sangat rendah tidak ada.

Data ini menunjukkan bahwa mahasiswa merasakan adanya kepuasan terhadap pemakaian edmodo di dalam membantu perkuliahan.

Visualisasi data di atas dapat dilihat pada gambar di bawah ini. 


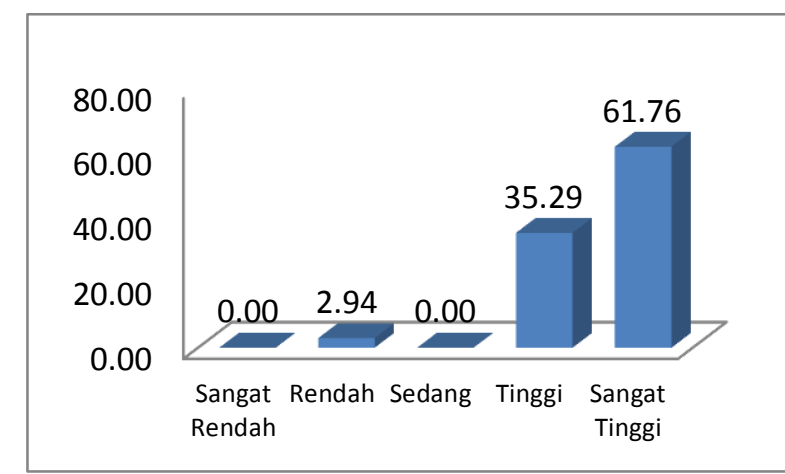

Gambar 10. Diagram skor kepuasan terhadap layanan edmodo

\section{SIMPULAN DAN SARAN Simpulan}

Berdasarkan hasil penelitian dan pembahasan di atas dapat disimpulkan bahwa:

1. Terjadi peningkatan secara signifikan peran edmodo dalam perkuliahan/pembelajaran. Dari data dapat diketahui $52,94 \%$ termasuk kategori tinggi, dan 38,24\% dalam kategori sangat tinggi.

2. Fitur edmodo sangat mendukung dalam pengelolaan KBM. Ini terlihat ada $44,12 \%$ responden menyatakan kategori sangat tinggi, dan 35,29\% dalam kategori sangat tinggi.

3. Tampilan edmodo sangat userfriendly, sehingga mudah dalam penggunaannya. Dari data diketahui $67,65 \%$ kategori tinggi, dan $14,71 \%$ dalam kategori sangat tinggi.

4. Mahasiswa merasakan tingkat kepuasan yang tinggi terhadap layanan edmodo ini . Dari data dapat diketahui $61,76 \%$ kategori sangat

\section{Implikasi} tinggi, dan 35,29\% termasuk kategori tinggi.

Penelitian ini memberikan implikasi kepada dosen dan mahasiswa serta pihak perguruan tinggi terkait. Keberhasilan sistem pembelajaran ini akan menjadi tolok ukur bagi dosen untuk menyiapkan diri mengikuti perkembangan teknologi terutama pada teknologi pendidikan saat ini. Bagi mahasiswa, sistem ini akan memberikan fleksibilitas dalam belajar dan memberikan kesempatan untuk bereksplorasi. Sedangkan bagi perguruan tinggi terkait, sistem ini memerlukan kepedulian PT untuk menyediakan sarana dan prasarana/infrastruktur jaringan TI.

Saran

Berdasarkan simpulan di atas peneliti mengajukan saran agar dosen selalu mengembangkan metode perkuliahannya dengan mengikuti perkembangan teknologi TI saat ini.

\section{DAFTAR PUSTAKA}

Amiroh. (2013). Antara Moodle, Edmodo dan schoology. Diambil tanggal 15 Maret 2013 dari http://amiroh.web.id/antaramoodle-edmodo-dan-schoology/

Azwar, Saifudin. 2013. Penyusunan Skala Psikologi. Yogyakarta: Pustaka Pelajar.

M. Zainal Abidin. (2012). Pemanfaatan Jejaring Edmodo dalam Pembelajaran Matematika. Diambil tanggal 15 Maret2013 dari http://www.masbied.com/2012/12/11/p emanfaatan-jejaring-edmodo-dalampembelajaran-matematika/

Khan, Badrul . (2005). Managing E-learning Strategies: Design, delivery, implementation and evaluation. Washington : Information Science Publishing.

Koran, Jaya Kumar C. (2002), Aplikasi ELearning dalam Pengajaran dan pembelajaran di Sekolah Malaysia. (8 November 2002).

Subagyo. (2007). Efektifitas Komunikasi Pembelajaran dengan mode Distance Learning Berbasis Website. Bogor (2013). Penerapan E-learning Berbasis Social Learning Network "Edmodo" Dalam Mata Pelajaran TIK Di Sekolah. Diambil tanggal 15 Maret 2013 dari https://sites.google.com/site/elearningp p09/e-learning/penerapan-e-learningberbasis-social-learning-networkedmodo-dalam-mata-pelajaran-tik-disekolah 